\title{
A condição expositiva e sua relação com o mercado de arte $^{1}$
}

EMERSON DIONISIO GOMES DE OLIVEIRA em Ciência da Informação (Organização da Informação), ambos da Universidade de Brasília. Membro do Grupo de Pesquisa "História da Arte: modos de ver, exibir e compreender". Autor de "Museus de Fora" (Zouk, 2010). Editor assistente da Revista MODOS.

$\overline{{ }^{1} E s t e}$ artigo é resultado de pesquisa financiada pelo CNPq 


\section{RESUMO}

O presente artigo busca posicionar uma história das exposições de arte frente a uma história do mercado de arte e suas instituições. Nessa perspectiva, optamos por construir um eixo entre exposições, mercados e museus. Eixo que seleciona pontos específicos de intersecção entre a história da arte e uma história das exposições. Por fim, apresentamos um problema para tal eixo, cuja premissa fundase na criação, pelos artistas, de novos regimes expositivos, capazes de desdobrar a obra de arte em diferentes modalidades de visibilidade. Condição que exige uma história da arte que lide com a transitoriedade da obra, sua tradução, sua reapresentação em distintas formas de exibição.

\section{PALAVRAS-CAVE}

História das exposições; arte contemporânea; mercado de arte; museus de arte.

\section{ABSTRACT}

The exhibition condition and its relationship with the art market. The present article seeks to position a history of the art exhibition in front of a history of the art Market and its institutions. From this perspective, we chose to build an axis between exhibitions, markets and museums. Axis that selects specific points of intersection between the history of art and a history of the exhibitions. Finally, we present a problem for such an axis, whose premise is based on the creation, by the artists, of new exhibition regimes, capable of unfolding the work of art in different modalities of visibility. A condition that requires a history of art that deals with the transitoriness of the work, its translation, its re-presentation in different forms of exhibition.

\section{KEYWORDS}

History of exhibitions; contemporary art; Art market; Art museums.

\section{Introdução}

Em fevereiro de 2017 o Museu de Arte Moderna de São Paulo apresentou a mostra "O mercado de arte moderna em São Paulo: 1947-51", com a curadoria de José Armando Pereira da Silva, cujo mote foi a comemoração de 70 anos da Galeria Domus, inaugurada em São Paulo no final dos anos de 1940. Na confluência que marcou a início da institucionalização da arte moderna no Brasil, a Domus, em cinco anos de existência e 91 exposições (KIYOMURA, 2017), significou o início de um longo processo de consolidação do mercado de arte brasileiro, especialmente devotado a produção daquele século. Tratava-se de um espaço, "ponto de encontro de europeus nostálgicos de um meio intelectual mais movimentado, [que] virou referência na vida cultural da cidade, lugar de reunião de músicos, artistas, literatos e críticos de arte" (BUENO, 2005, p. 386). As vésperas da fundação dos museus de arte moderna de São Paulo, Rio de Janeiro e Florianópolis, e antecedendo importantes galerias como São Luis (São Paulo, 1958), Astréia (São Paulo, 1959), Bonino (Rio de Janeiro, 1960), Petit Galerie (Rio de Janeiro, 1960), Atrium (São Paulo, 
1958), a Domus veiculou um modelo não usual para época: a confluência de artistas, críticos e colecionadores dentro de espaços comerciais, com forte presença na vida social das classes média e dirigente.

A mostra celebrativa do MAM-SP interessa-nos menos por sua condição particular - a galeria Domus - e mais por conjugar três instituições importantes do sistema da arte: o museu, o mercado e a exposição. O primeiro é facilmente reconhecível como uma instância institucional crucial para a manutenção do estatuto do artístico desde o final do século XVIII. O mercado, por sua vez, é uma instituição fragmentada, fundadora de um sistema que articula diversas unidades, sujeitos e dispositivos. Não raro podemos compreender o museu como parte do mercado da arte (BELTING, 2009). Já a exposição apresenta-se, inicialmente, como dispositivo operacional. Vista em particular, ela é uma instituição igualmente crucial tanto para a complexa relação entre instituições museológicas, quanto para a manutenção do mercado da arte. Assim sendo, tomamos a exposição como questão.

Nos parece inegável que a exposição, enquanto dispositivo integrante à condição de circulação, recepção e visibilidade da arte na modernidade, está intimamente vinculada às estratégias dos diferentes mercados das artes visuais, pelo menos nos últimos dois séculos. A exposição é a ação, o discurso e o processo mais conhecido para garantir o dar-a-ver a obra. Nesse sentido, o presente artigo busca apontar como a dissipação da/na arte contemporânea tem exigido regimes de expositividade compartilhados, em especial frente a uma produção descentralizada e fragmentada, que só se dá a ver pela reunião de diferentes parcelas de uma obra. Ou seja, a exposição, que ajudou a consolidar, sob os princípios de raridade, de originalidade, de estilo, de excepcionalidade, a ideia de uma obra una, indivisível, ajusta-se a uma produção que se dissipa. Mas antes, nos atentemos a uma história da exposição.

Sabedores, que uma história da exposição una e linear está fadada ao fracasso, basicamente porque este evento é marcado por sua heterogeneidade e por sua continua adaptabilidade. Do mesmo modo, uma história das artes e uma história das exposições não são intercambiáveis. Não tomemos uma pela outra como bem nos alertou Glicenstein (2009, p.251). Buscamos um caminho conciliador: fragmentos de uma história das exposições de arte, tomados pela relação entre a exposição e outras instituições do sistema da arte. Fragmentos que expressem a exposição enquanto evento que se transmutou em processo de distinção, em discurso organizador do olhar, em estratégia poética em sua condição contemporânea.

\section{Nem tão longe, nem tão perto: uma perspectiva histórica}

Toda obra de arte apresentada aos olhos do observador é uma obra exposta, seja numa parede de um palácio, num jardim burguês, num templo religioso ou numa praça. Todavia a exposição enquanto a reunião de obras de arte, temporariamente arranjadas para construir uma narrativa é um evento particular e 
intimamente ligado aos lugares e instituições modernas da arte ${ }^{2}$. Antes disso, a economia da encomenda foi o primeiro desafio da Exposição em sua relação com o sistema que criou, fomentou e consolidou o estatuto do artístico desde os quatrocentos. Tomando a realidade da península Itálica, Francis Haskell observou que no século XVII:

\begin{abstract}
Para elas [as exposições] aproveitavam-se sobretudo as inúmeras festas e procissões religiosas, que são um dos traços dominantes da vida no século XVII. A festa de Corpus Christi, em particular, sempre dava ocasião a uma exposição de quadros, mas não era a única. Segundo parece, não era fixado um local preciso aos artistas, é provável que expusessem indiscriminadamente junto com outros artesãos e comerciantes de arte que vinham mostrar seus produtos. (HASKELL, 1997, p.210).
\end{abstract}

Segundo o historiador da arte britânico as condições ofertadas pelas exposições não eram atraentes para os artistas renomados de outrora. Para estes, a exposição organizada por comerciantes de arte e antiguidades era um meio vulgar de divulgação do trabalho. Pintores e escultores reconhecidos faziam uso da lógica da encomenda, de contratos diretos, para instruir sua produção. De qualquer modo, as exposições nasceram para atender a uma demanda de visibilidade e, ao lado de outros bens, ajudaram a fundar um mercado especifico, já bastante perceptível na realidade dos Países Baixos no mesmo século.

No norte da Europa, em especial os Países Baixos, a exposição em lojas comerciais, antiquários e feiras era uma realidade que unia artistas de diferentes posições social e profissional, no que tradicionalmente denominamos como "mercado" de arte. Alpers (2010) lembra-nos que um artista neste período estava ao alcance da economia da encomenda, podendo ser demandado por burgomestres, aristocratas, dirigentes de várias organizações e comerciantes, entre outros mecenas. Todavia, ela é enfática ao afirmar que, ao contrário da realidade do resto do continente europeu, "produzir obras para o mercado era a regra e não a exceção para a maioria dos artistas holandeses" (idem, p.275). Mais que as mostras nas academias, nas confrarias e prefeituras, as exposições estavam associadas ao livre comércio das feiras. Neste caso particular, criou-se não apenas um mercado específico para pintura, dentro de um capitalismo em franco desenvolvimento, mas, também, para gravuras, para tapeçarias, para esculturas, compreendidas como artigos de luxo e de especulação.

\footnotetext{
2Jérôme Glicestein lembra-nos que uma história das exposições se deparou com a necessidade de definir um conceito de exposição. Ele toma a história da arte em contraponto, visto que a disciplina se debruçou sobre obras que não foram criadas no que entendemos como "arte" na atualidade. Assim a exposição poderia fazer o mesmo, numa construção fragmentada e mediada. Todavia, o autor opta por valorar uma história da exposição ocupada com o fenômeno expositivo, enquanto prática intencional. Momento em que a exposição é compreendida como prática de mediação, de comunicação, como fenômeno cultural reconhecível, tomando os salões do século XVII como marco possível (GLICESTEIN, 2009, p.241-251). No mesmo sentido, Jean-Marc

Poinsot reforça: "A exposição instaura uma lógica, uma sintagmática e uma concepção do signo que se encontra em comportamentos que ultrapassam amplamente os limites habituais da exposição no sentido estrito. É do conjunto do fenômeno da exposição e das práticas induzidas por ela que se trata aqui e não apenas, ter-se-á compreendido, da apresentação temporária de um artefato" (2012, p.163).
} 
Tanto no caso italiano como holandês, não contemos em encontrar um marco fundamental da história das exposições. Uma tarefa que pode ser tão infrutífera, quando fútil, por tentar celebrar uma nova história da arte, via exposições, pela reivindicação do valor de "origem". E, também, porque a depender da manipulação desse conceito podemos retornar aos mercados de esculturas e objetos decorativos da Antiguidade. Todavia, podemos tomar algumas mostras como pontuais e importantes para orientar uma história das exposições de arte. Uma delas foi a exposição organizada pela confraria de artistas, em Roma, chamada de Congregação dos Virtuosos. Tradicionalmente realizada no dia 19 de março no Panteão para celebrar o dia de São José ${ }^{3}$. Um dos propósitos desta confraria era "fazer das belas-artes um instrumento de glorificação da religião" (HASKELL, 1997, p.211). Com mais de um século e meio de existência, essa exposição, por sua periodicidade, tornou-se uma referência para a compreensão de como o sentido expositivo se desenvolvera. Dando ênfase a obras dos mestres do passado, a exposição romana, com restrições, também aceitava a produção de contemporâneos. Negando qualquer intenção comercial, o que the conferiu reputação até mesmo entre os artistas reconhecidos da época, como Salvador Rosa, Diego Velázquez e Giovani Sassoferrato, a exposição não negava sua intenção promocional. "Os artistas logo passaram a utilizar as exposições do Panteão como um meio de atrair para si mesmos a atenção do público" (idem).

O caso de Rosa é particular. Ele fora um artista que reconhecidamente se irritava com a falta de visibilidade de suas obras. Queixava-se que seus quadros encomendados eram apreciados apenas pelos compradores. Segundo Haskell (2000, p.9), Rosa se tornou um dos primeiros artistas a manifestar um pendor para a publicidade e para o reconhecimento de um "público". Mesmo com forte viés religioso, essas mostras ajudaram a construir um gosto e um público restrito para a arte. Tais exposições "davam um destaque muito maior aos mestres antigos do que aos artistas contemporâneos, e os mesmos quadros eram expostos repetidas vezes, ano após ano. Às vezes, porém, ofereciam ao público a ocasião de ver um gênero de pintura que normalmente não era acessível" (HASKELL, 1997, p.214). ${ }^{4}$

A exposição de obras para um público mais ou menos seleto já era uma condição dos programas das academias italianas do século XVII. Se tomarmos as mais antigas, Florença e Roma, tais instituições foram, inicialmente, configuradas como espaços sociais que buscavam representar os artistas, dissociando-os dos "meros artesãos competentes". Lentamente, as academias migraram para o modelo francês que preconizava um projeto de ensino das artes, sintetizado "por um programa de desenho a partir de modelo-vivo" (PEVSNER, 2005, p.137). Em poucas décadas, além das aulas, a maioria das academias de arte europeias já continham em seus estatutos a realização de conferências, premiações e exposições (idem, p.143).

\footnotetext{
${ }^{3}$ Uma outra exposição chamou a atenção de Haskell. Realizada no dia 29 de agosto no Mosteiro de San Giovanni, em homenagem ao dia do santo homônimo, organizada pelas "grandes famílias patrícias da cidade" (1997, p.212). Com o correr do século XVII, a exposição passou a dar evidente ênfase aos mestres desaparecidos, conferindo raro espaço para os artistas contemporâneos.

${ }^{4}$ Haskell salienta que as exposições, no século XVII, em Roma e Florença, foram as primeiras a insistir na apresentação de "mestres", eleitos e selecionados do passado próximo ou distante, na condição de exibir o poder e a opulência tanto das famílias colecionadoras, quanto de organizações e confrarias (2000, p.8-9). Portanto, as exposições, mesmo não sendo as criadoras $(2000, p .3)$, foram fortes divulgadores do conceito de "Old Master", tão importantes na criação e na consolidação da história da arte no século posterior. 
A seu tempo e modo, as exposições tinham finalidades semelhantes as suas correlatas modernas: serviam para exprimir um gosto dos organizadores, colecionadores; apresentavam uma seleção daquilo que cada período considerou como arte matricial, por meio, da seleção dos mestres do passado, ajudando a fundar no que seria conhecida como uma "história dos estilos" (escolas) de uma dada época ou região; permitiam aos artistas contemporâneos, em especial no norte da Europa, visibilidade para produção destinada à comercialização imediata; mesmo quando a negociação direta era interditada, a publicidade ofertada pela obra exposta facilitava transações posteriormente; constituía um público interessado, que não possuía alternativas para conhecer obras privadas e; graças a indícios e relatos esparsos, fomentava uma crítica incipiente, que já judiciava e hierarquizava a produção exposta.

Por sua vez, outro tipo de exposição ganhava corpo na França no século XVII. Uma mostra dedicada, ao contrário das estudadas por Haskell, à produção contemporânea: o salão. De certo, o salão é outra instituição da arte, cujas características excedem sua conjectura expositiva. Mas de qualquer maneira, um salão é sempre uma exposição. Nesse sentido, o salão-exposição, criado e associado ao sistema acadêmico, desde sua gênese, esteve próximo ao mercado da arte. Um mercado orientado pelo e para o Estado, que buscava no salão um modelo dissociativo do que deveria ser adquirido, celebrado, criticado, colecionado e reexibido. Katharina Hegewisch (2006) associa o salão não só ao surgimento de modelos que deveriam ser celebrados e copiados ou ao aparecimento de uma crítica especializada que forjava um novo vocabulário para o objeto de arte, mas, sobretudo, um evento aberto à constituição de um "novo" mercado, que legava à exposição a tarefa de propagar os modelos selecionados, dentro de um gosto "controlado" (HEGEWISCH, 2006, p.189).

Mesmo em dimensões distintas, as exposições organizadas por confrarias, aquelas produzidas pelos colecionadores, pelos nobres, pela Igreja ou pela Academia viam-se diante de um fenômeno distinto na segunda metade do século XVIII: a necessidade de instituir um público para arte. A exposição, em suas variações, chegara ao século XIX com a dupla e paradoxal condição: ao mesmo tempo que celebrava a independência da arte em um ambiente singular para sua existência, oferecendo ao artista novas possibilidades para alcançar compradores e colecionadores, a exposição associava-se às dinâmicas das mostras comercias e industriais, destinadas à celebração dos Estados Nacionais europeus, dentro de uma nova perspectiva colonialista. Assim, o mercado e antigas instituições reorganizaram-se para atender as novas dinâmicas estabelecidas:

Perfeitamente consciente de suas prerrogativas e de sua nova responsabilidade, a burguesia ascendente do século 19 certamente assumiu, com surpreendente naturalidade e grande eficácia, o mecenato dos artistas - que haviam perdido seus laços espirituais e estruturais com a Igreja e com o Palácio (...) Quando, já há muito tempo, foi perdido o consenso sobre a essência da arte, as exposições oficiais, isto é, legitimadas pelo Estado, continuaram a oferecer à burguesia uma ocasião de manifestar seu apreço a valores que foram ilustrados por uma pintura de salão altamente louvada - por péssimos motivos - e extremamente pouco inovadora (HEGEWISCH, 2006, p.185). 
Para Hegewisch, de modo geral e com raras exceções, a exposição tornouse um empreendimento bem-sucedido, pois a maior parte das associações e agremiações artísticas cobria suas despesas com os lucros obtidos com as mostras. É singular para os museus contemporâneos lembrar que os salões, em diferentes países, alcançavam facilmente mais de 100 mil visitantes. Mesmo quando não eram vinculadas à indústria ou com fins comerciais declarados, muitas mostras conseguiam razoável sucesso apenas com as entradas pagas pelos visitantes. Naquele século a exposição encontrava seu público, muitas vezes, independente do sucesso comercial das obras expostas (HEGEWISCH, 2006, p. 188). A atividade expositiva, portanto, ganhava uma relativa autonomia e passava a alimentar-se do público, que não necessariamente buscava os antigos ideais da arte, mas, por vezes, procurava a polêmica, as curiosidades, o divertimento social em suas salas e salões.

$\mathrm{O}$ ato expositivo passa a compor a agenda dos artistas. Ao longo do século XIX, a exposição tornou-se um elemento crucial para o amadurecimento de distintos mercados, para a consolidação da crítica, para o fortalecimento do sistema de ensino, para a manutenção do sistema museal e para o surgimento de galerias comerciais especializadas. Nos oitocentos, uma dialética entre o ateliê (o lugar do privado) e a exposição (o lugar público) estava fundada: a crença de que uma obra de arte só se revela quando deixava o isolamento do ateliê. Ao longo daquele século, o ateliê passa a ser considerado não mais como um espaço público, mas íntimo do artista:

\begin{abstract}
A exposição é, portanto, envolvida na estratégia de reconhecimento social do artista. Este evento é realizado em lugares distintos: uma vitrine, uma sala alugada para ocasião por um comerciante ou, mais frequentemente, no ateliê, que é muito afetado na reorganização da vida artística do século XIX. Apenas quanto o museu se torna o horizonte do trabalho artístico, o ateliê passa por uma metamorfose, para não dizer uma redefinição. De fato, desde o Renascimento, o ateliê era o espaço do artista: ele produzia suas obras, expunha-as aos mecenas, amigos, colegas... mas com a proliferação de exposições e o desenvolvimento do mercado, a exposição vai deixar o ateliê e se fixar residência em outro lugar diferente dele, a galeria ou o museu. (RODRIGUEZ, 2002, p.128, tradução livre).
\end{abstract}

Assim sendo, o museu consolida-se. A instituição toma forma e multiplicase. Ainda, em meados do século, as funções do museu moderno não estavam claras. "Seria o museu uma escola, um lugar de entretenimento ou um lugar de fruição estética? Debatia-se a propósito daqueles que sabem ou não ver uma obra de arte ("oculos habent et non vident")..." (GEORGEL, 2015, p.280). Nesse debate o museu lentamente se consolida "como o lugar por excelência de exposição" (idem, p.285). Assim, os eventos expositivos se multiplicaram. Enquanto o final do século terminaria com a criação de uma grande exposição de arte - a Bienal Internacional de 
Veneza -, que logo se tornaria referência para o sistema no século seguinte ${ }^{5}$, as exposições passaram a constituir-se em estratégia para os próprios artistas, que independentemente das instituições consagradas de outrora. Bastante conhecido é o exemplo de Gustav Courbet, que em 1855 recusou-se a participar da Feira Universal de Paris. A feira havia convidado cinco grandes mestres da pintura para construir salas retrospectivas, mas Courbet, por diferenças políticas, optou por construir um pavilhão próprio (RODRIGUEZ, 2002). Um número considerável de artistas antes do pintor realista francês organizou suas próprias mostras, definindo não só o que e como expor, mas, também, assumindo as finanças do empreendimento. Todavia, o pavilhão de Courbet funcionava como uma poderosa metáfora para marcar a mudança operada pelos artistas modernos. Com uma exposição nas vizinhanças da feira, a exposição do artista mostrava uma indisposição para com as grandes instituições, mas uma proximidade simbiótica era admitida. Nem tão longe, nem tão perto.

O novo sistema instaurado na segunda metade do século era, por sua vez, altamente dependente da exposição como ação propulsora. Tal sistema funcionava a partir do duo marchand-crítico, tendo numa ponta o artista e na outra o colecionador. Ampliando a perspectiva ofertada pelos White ${ }^{6}$, a exposição oferecia a cada um desses sujeitos novas oportunidades alternativas de circulação da arte: "A multiplicação de exposições individuais e de grupos estava cada vez mais direcionada ao comércio da arte, o que funcionou, gradualmente, como solução para um dos problemas colados pelos salões do século XIX: o apoio oferecido às carreiras dos artistas" (VAISSE, 1995, p.107, tradução livre).

Joyeux-Prunel mostra-nos como artistas franceses de vanguarda, ao lado de marchands e críticos, utilizaram a exposição como estratégia de difusão de obras de arte de diferentes vocabulários estéticos. Enquanto apresentavam suas obras "experimentais" em Paris, expunham em outras cidades europeias obras mais "aceitáveis". "As vanguardas não se impuseram apenas por sua genialidade, elas foram capazes de inventar e impor o seu lugar na sociedade e na arte de seu tempo por meio de estratégias de criação, de exposição e de discurso" (JOYEUXPRUNEL, 2016, p. 86).

Foi nesse momento que a exposição passou a ser assimilada pela lógica produtiva do artista. Jean Marc-Poinsot chama atenção para esse processo: na história do modernismo, a exposição torna-se parte "pressuposta da obra", fundando a contradição entre "obra autônoma" e "obra exposta", em detrimento

\footnotetext{
${ }^{5}$ Moulin lembra-nos sobre a eficácia desse modelo, ainda, no final do século XX: "As grandes manifestações internacionais, como a Bienal de Veneza ou a Documenta de Kassel, marcam os encontros periódicos do mundo cosmopolita da arte internacional. (...). Os próprios artistas ali se encontram confrontados com a imagem social de sua obra, assim como outras correntes estéticas. Essas manifestações exercem também, como o Salão de Paris no século XIX, uma função de qualificação dos criadores. Agindo como academias informais, elas participam da elaboração de um quadro-de-honra dos valores estéticos e constituem as etapas da reputação do autor e do preço das obras. (MOULIN, 2007, p.30).

${ }^{6}$ Pesquisando a produção de pintura francesa na segunda metade do século XIX, os sociólogos Harrison e Cynthia White batizaram o relacionamento entre marchands, críticos, colecionadores e artistas de "dealer-critic system". (MOULIN, 2007).
} 
desta última (2012, p.156; p.166). ${ }^{7}$ Os artistas reagiram de modo peculiar ao fenômeno. Se em 1874, sob a liderança de Claude Monet, os artistas alugavam seus próprios espaços para expor uma produção carente de um público de "vanguarda", Dulguerova (2007) mostra-nos que os artistas de vanguarda do início do século XX já estavam conscientes de que a exposição é uma prática em busca de seu próprio público e precisa ser "construída". As práticas expositivas herdadas dos oitocentos não eram mais possíveis. A moldura não mais protegia a condição da obra e todo um novo discurso expográfico precisou ser criado para acolher não apenas as obras, mas, sobretudo, para catalisar um novo modo de ver.

Nesse momento que a exposição se transforma num evento "discursivo". Um evento capaz de criar relações entre as obras, de instaurar e defender ideais. Rapidamente, segundo Bal (2007), o mercado de arte compreendeu que a lógica da exposição era traduzir em linguagem visual conceitos e ideias intelectuais e estéticos. ${ }^{8}$ Já para os artistas das vanguardas históricas a prática expositiva foi "um meio de produzir um espaço público capaz de agir sobre a história" (DULGUEROVA, 2007, p.74). Construir e instruir um público particular, em favor de uma ideia ou de uma venda, a exposição vincula-se definitivamente aqueles que olham. $\mathrm{O}$ advento do cubo branco torna-se chave na recaracterização dos espaços habitados não mais pela arte, mas pela relação entre obra-público.

Como espaço temporário autorizado da arte do século $\mathrm{XX}$, a exposição passou a se constituir numa instituição que opera para além de sua efemeridade e sua transitoriedade (DULGUEROVA, 2007, p.76). Transforma-se numa situação de discurso para além do evento, estendendo seus sentidos a partir das obras e sobre as obras mesmo depois do termino, graças a todo um conjunto de signos abertos por ela ${ }^{9}$. Como em qualquer instituição consciente do discurso que funda, uma genealogia fora construída para autorizar esse "novo" meio. Das Sessões em Viena, Berlim, Munique, Bruxelas entre outras cidades europeias no início do século, passando pelas exposições futuristas de Tatlin e Malevitch (1915), Exposição Proun (1923) de El Lissitzky, até a Exposição Internacional do Surrealista (1938), um elenco de mostras passou a guiar uma história das exposições do período (KLÛSER, B.; HEGEWISCH, K., 1998). As mostras são entrelaçadas com a produção artística que apresentam e se transformam, elas mesmas, em projetos estéticos apreciáveis. Como em qualquer genealogia convencional, encontramos o elenco que marcou o século XX: artistas, gestores, marchands, colecionadores, críticos, curadores:

\footnotetext{
$\overline{7}$ Poinsot, ao debater pressupostos defendidos em textos de Rosalind Krauss, lembra-nos a despeito dessa dicotomia, que: "Ignorar o enquadramento ou o pedestal, ou reduzir o que implica sua absorção pela obra num processo de autonomização sem levar em conta a transformação concomitante do enquadramento mais geral no qual a obra tende a acontecer desde o fim do século XIX é recusar a dimensão discursiva que a prática da exposição introduziu. Assim, sob a capa de uma história da arte formalista, considerando-se a si mesma autônoma face às visões imperialistas dos saberes vizinhos, e fundando sua legitimidade em sua pressuposta adaptação ao estudo da arte moderna, foi de certa maneira proibido falar da maneira como a obra acontecia, do acontecimento de seu advento." (2012; p.157)

${ }^{8}$ Mieke Bal defende o espaço expositivo moderno como aquele capaz de autorizar um discurso lógico, geralmente linear, e de criar, alterar e reforçar as práticas do olhar ocidental, na medida que escolhe um modelo orientador para o visitante (BAL, 1996, p. 8-9).

${ }^{9}$ Numa perspectiva anacrônica, podemos julgar que nesse momento surge o que será conhecido por nós como a dissociação entre expografia e museografia. Enquanto a primeira está associada ao desenho da exposição e suas relações espaciais; a segunda implica, além da expografia, todo o conjunto de fatores que afetam a exposição: curadoria, arquitetura, acessibilidade, registros e documentação, conservação, ações de mediação etc.
} 
Toda vanguarda tem seus intérpretes. As exposições programáticas como Sonderbund ou o Armory-show, como o Salão de outono de Walden ou a Documenta de Arnold Bode implicam também, a despeito da tolerância e da disposição com pontos de vista contraditórios, uma decisão subjetiva contra ou a favor de certas posições. A escolha é um pressuposto incontornável de toda exposição (HEGEWISCH, 2006, p.192).

Ao analisar exposições produzidas por El Lissitzky, Hebert Bayer e Phillip Johnson, Glicenstein defende os anos de 1920 e 1930 como uma "idade do ouro" da exposição cenográfica, uma vez que os artistas, os arquitetos e os designers não mais construíam suas expografias a partir das obras, mas tomavam-nas dentro de um espaço capaz de afetar fisiológica e psicologicamente o espectador (GLICENSTEIN, 2009, p.46-47). Além do espectador, para parte das vanguardas históricas foi preciso construir um espaço onde as obras interagissem entre elas, construindo um espaço de representação próprio. Tal espaço baseou-se, segundo Dulguerova (2007, p.82), em dois discursos visuais distintos. O primeiro herdado do museu, que celebrava um tempo-espaço verídico e atemporal, e o segundo proveniente da feira, cujas possibilidades residiam no consumo visual imediato. Tais discursos ajudaram a construir a exposição como singularidade, como espaço único e, por conseguinte, como "mercadoria" distinta e autoral.

\section{A banda dos sete}

A segunda metade do século vê o advento de uma multiplicidade de novas linguagens, processos experimentais e novos agentes vinculados ao sistema da arte. Embora, ainda, possamos falar de um circuito operado por artistas, críticos, marchands e colecionadores, mais os menos vinculados as galerias, museus, bienais, feiras etc; o mundo da arte não foi mais o mesmo com o aparecimento do curador. Melhor dizer, com o surgimento de um discurso curatorial distinto daquele formatado pelo tradicional conservador de museus e de coleções. Este novo discurso surgiu como intermediário entre todos aqueles sujeitos. Função mais que profissão, todos os agentes do sistema passaram mais ou menos a operar a partir do dispositivo curatorial. Dentre as diferentes funções de um curador - e não são poucas $^{10}$ - podemos destacar dois níveis reconhecíveis e não exclusivos: o curador de coleções e o curador de exposições.

Heinich e Pollak lembram-nos que atuando dentro das instituições ou paralelo a elas, o curador de exposições logo solicitou um lugar de "autor" (1996) na engenharia do "mundo da arte". Nessa perspectiva, ao menos desde os anos de

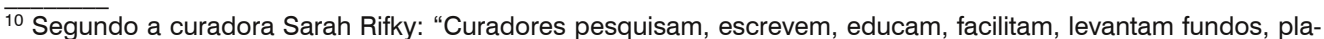
nejam, dirigem, produzem, criam e cuidam dos artistas, obras e exposições desde seu estágio inicial como ideia até muito depois que acontecem. Documentam, promovem, apresentam e reapresentam projetos passados, enquanto buscam novos projetos o tempo todo. Formam redes, reúnem ideias e constroem públicos; trabalham de forma fluida e independente, dentro, através de, em relação a, com e fora de instituições. Articulam conceitos, vendem branding e projetos, e medeiam polos e atores do campo da arte. São pêndulo entre a prática e a teoria, entre a arte e sua história. Curadores também fazem as vezes de críticos, quando estes se ausentam" (apud MADZOSKI, 2014, p.156).
} 
1970, o curador responsável por "construir" o discurso expositivo (e a partir dele uma cadeia de discursos auxiliares) demandou uma autoria particular. Não se trata mais de organizadores de coleções que organizam exposições, mas sim autores como Germano Celant, Harald Szeemann, Lucy Lippard, Achille Bonito Oliva, Jan Hoet, Willian Rubin, Willian Sandberg, Kaspar König ${ }^{11}$, entre tantos outros, que introduziram com suas mostras um aparato conceitual, crítico e político sem precedentes até os anos de 1960. Uma nova coalização surgiria entre esses novos agentes do sistema da arte e os tradicionais sujeitos, transformando o modo como as exposições serão constituídas e comercializadas.

Ao mesmo tempo em que a exposição se tornou linguagem para artistas como Yves Klein, Robert Morris, Michael Ascher, Daniel Buren, Joseph Beuys, Hans Haacke, Graciela Carnevale, Marcel Broodthaers, Claes Oldenburg, Christian Boltanski, Susan Hiller, Nelson Leirner, entre tantos outros, ela também se transformou em espaço de disputas entre diferentes posições, saberes, discursos e mercados (MADZOSKI, 2014). Para Mary Anne Staniszewski há uma convergência entre esses dois fenômenos que se debruçam sobre o espaço da exposição e sua relação com as obras. É sintomático perceber que no momento em que a exposição se torna plenamente autoral foi antecedido pela produção in-situ, dependente e transformadora do lugar que ocupava (apud BISHOP, 2015, p.271). Na perspectiva do mercado, quando a arte contemporânea se dissipa no espaço, o curador surge como o organizador, mediador e interprete necessário para instruir, no sistema, um público almejado.

Assim temos uma mudança efetiva no último quarto do século XX no modo como os sujeitos do "mundo da arte" e suas instituições acionam as práticas expositivas. A obra abandona sua "autonomia" em relação ao espaço, contaminando-o, veiculando-o ou simplesmente recriando seus sentidos. Assim, a exposição, diante da arte contemporânea e do curador, líder inconteste na mediação entre artistas e mercado, transforma-se em tática para posicionar e reposicionar obras do presente (e do passado). Uma obra, mais do que antes, precisa habitar diferentes e múltiplas enunciações, absorvendo e contradizendo suas diferenças, nos distintos regimes expositivos oferecidos, como esclarece Marina Romiszowska, então curadora da feira Art Rio:

\begin{abstract}
Para manter um funcionamento dinâmico do mercado de arte é interessante manipular as relações comerciais na direção da descentralização, da democratização e da universalidade. Portanto, o mercado passou a abrigar diversos modelos expositivos, desde os tradicionais, que são ainda os mais alinhados a um conceito cultivado pela história da arte, até os outros modelos da contracultura, que se rebela contra ela ou ampliam seus limites (apud VELLOSO et.all, 2013, p.137).
\end{abstract}

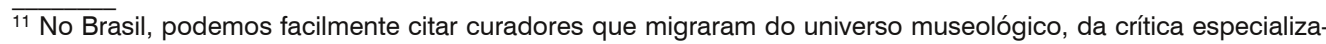
da ou dos bancos universitários como: Walter Zanini, Aracy Amaral, Frederico Morais, Aline Figueiredo, Roberto Pontual, Frederico Morais, Sheila Leirner, Adalice Araújo, entre outros. 
A questão torna-se mais evidente quando tratamos de obras que em sua constituição cruzam diferentes linguagens e que, por conseguinte, recorrem a condições hibridas de visibilidade. Performances que se estendem em foto-performances ou vídeo-performances. Intervenções urbanas que se transformam em pinturas. Instalações que utilizam a linguagem cinematográfica. Vídeos que são apresentados e associados a objetos. Os exemplos se multiplicam.

Tais obras exigem de críticos, curadores, historiadores da arte, educadores e gestores a capacidade de compreender, de conservar, de narrar e de expor obras em trajetória, em plena condição intermidial (BELTING, 2014). Buscar uma unidade nessas obras pode ser frustrante, pois diferentes regimes expositivos são acionados. Tomemos como um problema a videoinstalação "A banda dos sete" de Sara Ramo, apresentada em 2010, na Bienal de São Paulo daquele ano, atualmente no acervo da Pinacoteca do Estado de São Paulo (fig.1). A obra foi a terceira videoinstalação adquirida pelo museu paulista em 2014; numa negociação entre museu e mercado. ${ }^{12}$

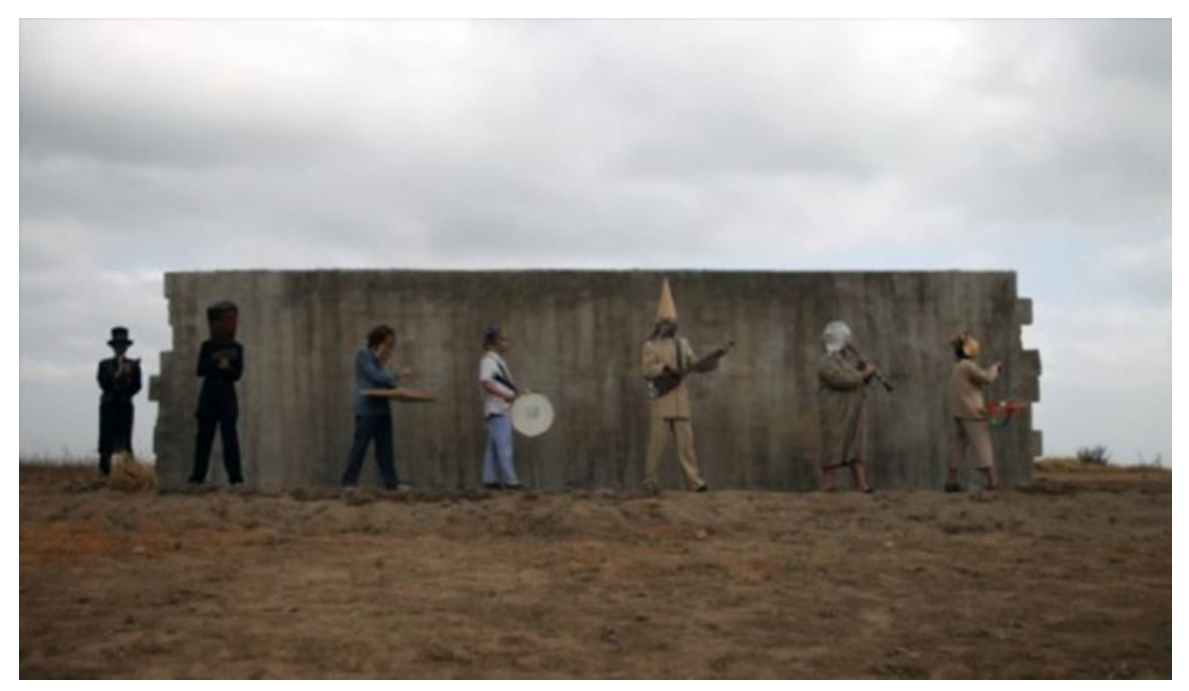

Figura 1.Frame do vídeo "A Banda dos Sete" (2010).

Fonte: <https://www.youtube.com/watch?v=mogDYPKtseM>

Ramo é uma artista preocupada com a condição contemporânea da acumulação, do utilitarismo, do programático, especialmente naquilo que atinge a construção da "imaginação" em nosso cotidiano (TORNER, 2013). "A banda dos sete" foi concebida de modo a especular os limites entre linguagens:

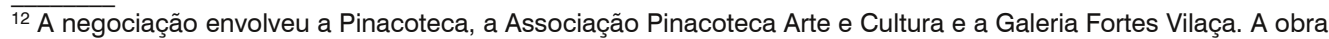
fora adquirida pelo valor de $\mathrm{R} \$ 44$ mil reais. Informações contidas na Ficha catalográfica (item 9388) disponível no setor de Museologia da Pinacoteca do Estado. Agradeço a pesquisadora e museóloga Tainá Mara Moreira Xavier pelas informações fornecidas sobre a obra.
} 
Começou com a obsessão do muro, o muro como tela e os músicos passando ao longo do muro. Estava imaginando como seria aquela banda da pequena vila que toca nos dias de festa, como na música do Chico [Burque de Holanda], mas na minha cabeça era uma banda sem espectadores, uma banda que tocava por tocar. Conversando com alguns amigos músicos, a questão da melodia e ritmo começou a tomar mais importância, eles perguntavam se eu pensava em instrumentos de vento ou de metal, em como ia acontecer o descompasso... Trabalhei com Ivan Canteli, que foi o diretor musical, e essa troca é que foi realmente interessante, pois além de compor a melodia, me ajudou a pensar em música, que é uma matemática que eu tentava embaralhar a partir de conceitos como Fuga ou Canon, e isto era novo para mim. Ao fazer o vídeo, era importante fazer coincidir a música e a imagem, tínhamos que organizar a bagunça para dar pautas aos músicos. O vídeo funciona como uma caixa de música, como uma espécie de eterna repetição aleatória. E é importante nele a ideia do funcionamento de um grupo e suas individualidades, e nisto a formação de uma banda funciona como um catalisador perfeito. ${ }^{13}$

Como a reunião de música, performance e vídeo de aproximadamente 21 minutos, a obra participou de Mostra Competitiva de curtas e médias metragens do Cine Esquema Novo, em Porto Alegre, cujo regime expositivo adequa-se à tradição cinematográfica ${ }^{14}$. Com forte poder narrativo, quando projetado sobre um espaço arquitetônico, "A banda dos sete" amplia sua condição, para além do cinematográfico, ao instaurar e criar um espaço próprio. Na medida em que a obra é instalada dentro dos espaços museais dedicados às artes visuais, a condição legitimadora de tais espaços altera a percepção sobre ela. A literatura entre passagem da "sala preta" para o "cubo branco" nos adverte sobre as mudanças de recepção e como os espaços realinham a obra em mercados não necessariamente vinculados (CIFUENTES, 2011). Todavia, a obra de Ramo, ainda, ganha desdobramento quando o vídeo alcança a exposição "aberta" da internet: o vídeo esteve por alguns meses disponível na plataforma online de compartilhamento YouTube, no canal da Galeria Fortes Vilaça. ${ }^{15}$ Atualmente a videoinstalação pode ser encontrada em outros sítios. ${ }^{16}$

\section{Algumas considerações}

Tomada em sua condição intencional a obra de Ramo já nasceu fundindo linguagens distintas. Ao mesmo tempo, uma aproximação de seus regimes de

\footnotetext{
${ }_{13}$ Site-blog do Festival Cine Esquema Novo Cinema. Entrevista com a artista Sara Ramo. Disponível em: $<$ https://cineesquemanovo.wordpress.com/2011/04/11/entrevista-sara-ramo-realizadora-de-\%E2\%80\%9Ca-banda-dos-7\%E2\%80\%9D/>; acesso em março de 2017.

${ }^{14}$ Apresentada ora como vídeo-arte, ora como videoinstalação a obra percorreu outras mostras antes do ingresso no museu. Além da Galeria Fortes Vilaça a obra pode ser vista na: Exposição "Uncertain Trialectis" na Suécia em 2012; "HBOX", em dois momentos diferentes de 2011 na Coreia do Sul e China; no "Project 35" no Canadá em 2013; "Imagine Brazil" na Noruega em 2014; "100 anos da Pinacoteca no MUnA", em 2014, além do festival de cinema da capital gaúcha.

${ }^{15}$ Filme completo da obra era acessado até recentemente pelo endereço <https://www.youtube.com/wat$c h ? v=H f R E s 6$ PUoO0 > ; primeiro acesso em abril de 2016.

16 Ver, por exemplo, a conta da curadora Daniela Name no YouTube. Disponível em: <https://www.youtube.com/watch?v=mogDYPKtseM >; acesso em abril de 2017. 
exposição multiplica sua visibilidade e oferece uma obra em trajetória. A obra exposta da galeria ou no museu é apenas uma dimensão possível da "A banda dos sete". O exemplo é diminuto perto do continente possível na configuração do eixo que propomos (exposições, mercados e museus) e na frente aberta por esse rápido exercício analítico (uma história das exposições de arte frente a uma história do mercado de arte e suas instituições), mas é suficiente para abrigar inquietações e alertar historiadores da arte, em particular, de que não se pode tratar a história do dar-a-ver como circunstância acessória, para usar o termo de Poinsot (2012, p.177). Se não é recomendável perceber a obras do passado fora de seus sistemas de circulação, percepção e crítica, torna-se mais difícil diante de obras como a produzida por Ramo.

As exposições na contemporaneidade obedecem a lógica da dissipação na atualidade. Participam de uma rede de ações expositivas que lançam a obra numa cadeia de visibilidade, impulsionadas por um mercado ávido por promovê-la. $\mathrm{Na}$ atualidade, além de dispositivos poéticos e conceituais, as exposições permitem a valorização das obras, dos artistas e dos demais sujeitos a eles vinculados, possibilitando "um aumento do valor das obras, aumento do prestígio, multiplicação dos convites para participar de outros eventos, publicações, marketing gratuito" (FIALHO, 2005, p.695).

Ainda temos salões de arte, exposições retrospectivas, coletivas temáticas e mostras transnacionais. Temos individuais em pequenas galerias, mostras de jovens coletivos, "exposições selvagens" da contracultura (GREFFE, 2013, p.138), sites e novas mídias que oferecem expositividade contínua e regimes de arquivamento compartilhados. Temos intervenções em áreas urbanas, performances em espaços alternativos preocupados na recontextualização de novos sítios e na ampliação do sentido de espaço de exposição e "obra exposta". Temos projetos curatoriais work-progress, exposições institucionais-coorporativas e em galerias experimentais. Bienais, feiras e museus compartilham obras em distintos projetos expositivos. Casas de leilões, grandes galerias (como a Domus foi no passado) e projetos comunais se antagonizam, por vezes, utilizando as mesmas obras. Os vernissages e as encomendas resistem. Ou seja, uma miríade de formas de mostrar uma obra de arte se acumulam na contemporaneidade. Diferentes mercados que formam o sistema da arte se organizam para compor suas estratégias expositivas, alterando em cada momento o que tradicionalmente conhecemos como obra de arte e o modo de interpretá-la e narrá-la.

\section{Referências}

ALPERS, S. "Liberdade, arte e dinheiro". In: O projeto de Rembrandt: o ateliê e o mercado. São Paulo: Cia das Letras, 2010, 230-312.

BAXANDALL, M. O Olhar Renascente. Rio de Janeiro: Paz e Terra, 1991.

DULGUEROVA, E. L'exposition: um espace public contingente chez les avant-gardes historiques

(1910-1920). In: CAILLET, E.; PERRET,C. L'art contemporain et son exposition II. Paris: L'Harmattan, 2007 
BAL, M. Double exposures: the subject of Cultural Analysis. Nova York; Londres: Routledge, 1996.

BAL, M. "Le public n'existe pas". In: CAILLET, E.; PERRET,C. L'art contemporain et son exposition II. Paris: L'Harmattan, 2007.

BELTING, H. "Contemporary Art as Global Art A Critical Estimate". In: Hans BELTING, H.; BUDDENSIEG, A. (eds.). The Global Art World, Ostfildern, 2009.

BELTING, H. Antropologia da Imagem. Para uma ciência da imagem. Lisboa: KKYM; Escola de Arquitetura da Universidade do Minho, 2014.

BISHOP, C. "O que é um curador? A ascensão (e queda?) do curador auteur". Revista Concinnitas, ano 16, vol.2, dez. 2015, p.270-282.

CIFUENTES, A. "Entre a caixa preta e o cubo branco: o vídeo, a imagem-movimento no contexto das artes plásticas”. Revista Pós, Belo Horizonte, vol.1., no2, p.59-74, 2011.

DULGUEROVA, E. L'exposition: um espace public contingente chez les avant-gardes historiques (19101920). In: CAILLET, E.; PERRET,C. L'art contemporain et son exposition II. Paris: L'Harmattan, 2007.

FIALHO, A.L. "As exposições internacionais de arte brasileira: discursos, práticas e interesses em jogo". Sociedade e Estado, Brasília, v. 20, n. 3, set.-dez., 2005, p. 689-713.

GEORGEL, C. "O colecionador e o museu, ou como mudar a história da arte?", Revista Museologia e Interdisciplinaridade. Trad. Ana Cavalcanti. PPGCING-UnB, vol.3, n6, março/abril de 2015, p.277-286.

GLICENSTEIN, J. L’Art: Une Histoire d’Expositions. Paris: Presses Universitaires de France, 2009.

GREFFE, X. Arte e Mercado. São Paulo: lluminaras; Itaú Cultural, 2013.

HASKELL, F. Mecenas e pintores: arte e sociedade na Itália Barroca. São Paulo: Edusp, 1997.

HASKELL, F. The ephemeral museum: old master paintings and the rise of the art exhibition. New Haven: London: Yale University Press, 2000.

HEGEWISCH, K. Um meio à procura de sua forma. As exposições e suas determinações. Arte \& Ensaios, nำ13, 2006.

HEINICH, N.; POLLAK, M. From Museum Curator to Exhibition Autor: investing a singular position. In: GREENBERG, R.; FERGSON, B; AIRNE, S. (org.). Thinking about exhibitions. Londres; Nova York: Routledge, 1996, p.231-250.

JOYEUX-PRUNEL, B. "A internacionalização da pintura vanguardista, de Courbet a Picasso: uma transferência cultural e seus quiproquós". Revista VIS. Programa de Pós-graduação em Arte da UnB Vol.15, no2,/julho-dezembro de 2016, p.61-88. 
KIYOMURA, L. "Os modernos voltam a se encontrar", Jornal da USP, 01 fev de 2017; disponível em: <http://jornal.usp.br/cultura/os-modernos-voltam-a-se-encontrar/>; acesso em março de 2017.

KLÜSER, B.; HEGEWISCH, K. (orgs.) L'art de l'exposition: une documentation sur trente expositions exemplaires du XXe siècle. Paris: Le Regard, 1998.

MADZOSKI, Vesna. "A invenção dos curadores". Arte \& Ensaios, dezembro de 2014, n²8, p.145-165.

MOULIN, R O mercado da arte: mundialização e novas tecnologias. Trad. Daniela Kern. Porto Alegre:Zouk, 2007.

PEVSNER, N. Academias de arte: passado e presente. São Paulo: Cia das Letras, 2005.

POINSOT, J. -M. "A arte exposta: o advento da obra”. In: HUCHET, S. (Org.). Fragmentos de uma teoria da arte. São Paulo: Edusp, 2012. p. 145.

RODRIGUEZ, V. L'atelier et l'exposition, deux espaces en tension entre l'origine et la diffusion de l'oeuvre, Sociologie et sociétés, no 342, Universidade de Montreal, 2002, p. 121-138.

TORNER, M.B. "El universo fantástico de Sara Ramo". Revista: Estúdio, Artistas sobre outras obras, vol 4 (7), p.190-193.

VAISSE, P. La Troisième République et les peintres. Coll. Art, Histoire et Société. Paris: Flammarion, 1995.

Recebido em 15/06/2017 - Aprovado em 23/07/2017 